\title{
The effects of CR-contingent UCS presentations in eyelid conditioning
}

GLENN E. MACDONALD, GERALD J. LEVINE AND ABRAM AMSEL

UNIVERSITY OF TORONTO

\begin{abstract}
The performance of $16 \mathrm{Ss}$ in an eyelid conditioning procedure which involved presentation of the UCS to the open eye immediately following one half the CRs (contingent partial delay) was compared to performance of $\mathrm{Ss}$ in regular continuous conditioning regular partial conditioning and partial noncontingent UCS delay conditioning. It was found that the level of responding of the contingent partial delay group was equal to the continuous group and superior to the other two groups. These results suggest the need for a re-interpretation of reinforcement and nonreinforcement in aversive conditioning.

\section{Problem}

It has been demonstrated by Spence $(1960$, p. 172) that performance in eyelid conditioning is a function of the number and kind of UCS presentations. The fact that the UCS is regarded as the source of drive has caused difficulties in interpreting mechanisms of reinforcement in eyelid conditioning, particularly as they operate in partial reinforcement situations. Since partial reinforcement typically involves the omission of the UCS, the reinforcement schedule and number of UCS presentations are confounded.

Attempts have been made to solve this problem by using a UCS delay procedure instead of UCS omission (Moore \& Gormezano, 1963). However, the delay procedure does not take into account the possible instrumental reinforcing effects produced by an anticipatory blink.

It is possible, therefore, to conceive of an anticipatory blink which may be elicited by the CS but partly blocks the air puff as a reinforced trial and of anticipatory blink which occurs but is immediately followed by an air puff to the naked cornea as a non-reinforced trial. The purpose of the present investigation was to study performance under such conditions and compare the results to those obtained under US omission and UCS delay.

\section{Method}

The Toronto eyelid conditioning laboratory is similar in all respects to that described by Spence (1953). The Ss wore a headband which supported an airjet and microtorque potentioneter for recording eyelid movements. The UCS was a 1.5 psi puff of compressed nitrogen of $50 \mathrm{msec}$. duration. The CS was an increase in brightness of a $6 . \mathrm{cm}$ milk glass disc. Sixty-four female Ss received 20 acquisition trials in which a UCS was presented on all trials, the CS-UCS interval being $500 \mathrm{msec}$. These Ss were then divided into four experimental groups of 16 each. The continuous reinforcement group (Group C) received the UCS on all acquisition trials, the CS-UCS interval being $500 \mathrm{msec}$. The contingent partial delay group (Group CPD) received the UCS $500 \mathrm{msec}$. after the CS on $50 \%$ of the trials and received the UCS on the other $50 \%$ of the trials immediately after the CR had beer completed and the eyelid had opened again. On these latter $50 \%$ of the trials, no UCS was delivered if there was no CR.

The classical partial delay group (Group PD) received the UCS $500 \mathrm{msec}$. following the CS on $50 \%$ of the trials and on the other $50 \%$ of the trials received the UCS at the same time and on the same trials as it was presented in Group CPD, but not contingent on $\mathrm{S}$ making a CR. The partial group (Group P) received the UCS on $50 \%$ of the trials and no UCS on the other $50 \%$.

In the contingent delay group, the air puff was manipulated by $\mathrm{E}$ who decided through monitoring the record whether or not the $\mathrm{S}$ had made a CR. The accuracy of these manipulations and decisions were later checked against the graphic record and it was found that $\mathrm{E}$ had made about $2 \%$ errors in judging the presence of CRs, but that he had been able to manipulate the air puff so that it always fell on the open eye with less than $500 \mathrm{msec}$. delay.

The overall experimental session involved CS-UCS pairings with a $500 \mathrm{msec}$. interval for all $\mathrm{Ss}$, followed by a further 80 acquisition trials under the appropriate experimental conditions, followed by 20 extinction trials. Eyeblinks occurring in the interval 150-500 msec. in acquisition and in the interval 150-550 msec. in extinction were scored as CRs.

\section{Results and Discussion}

The percentages of CRs in acquisition and extinction for the four groups are presented in Fig. 1, which reveals that at the end of Trial 20 there were some slight differences among the groups. Since all groups had received identical treatment to this point, these differences were a result of chance variation. Therefore, the level of responding in Trial 20 was used as a covariant in the subsequent statistical analyses.

Figure 1 shows that both Group C and Group CPD attained asymptotic levels of approximately $80 \%$ CR whereas Groups PS and P were both near 60\%. Analysis of covariance for Blocks 3 to 10, using performance on Block 2 as a covariant, revealed significant differences among groups $(F=8.09 ; \mathrm{df}=1 / 59 ; \mathrm{p}<.001)$ Further comparisons on Block 10 indicated that Groups $\mathrm{C}$ and CPD were not significantly different from one 


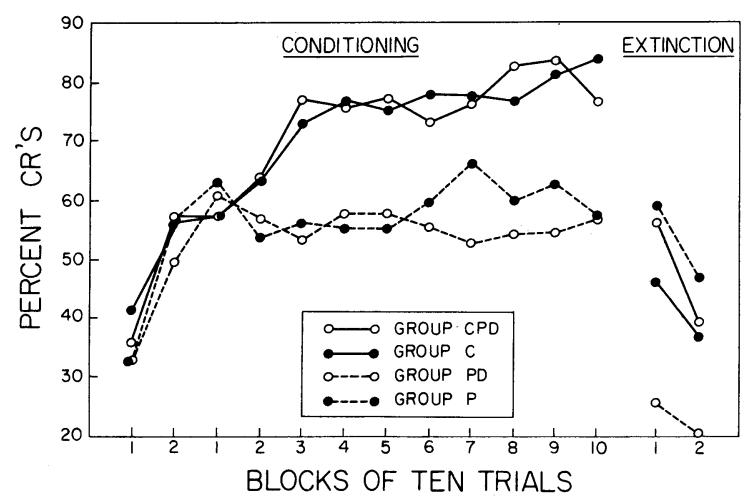

Fig. 1. The percentage of CRs plotted in 10-trial blocks during acquisition and extinction.

another, and that Groups PD and P were not significantly different either.

The results for extinction suggested that the two partial groups (Group CPD and P) showed more CRs in extinction than the control group and that the classical delay group was subject to very rapid extinction. However, analyses of these results did not reveal any significant differences.

The major finding of this study is the difference between groups CPD and PD. These two groups differ only with respect to the contingency of the UCS and CRs in the CPD group. The effect of this contingency is that in the CPD group the UCS occurs in careful relation to each S's own latency of CR, and that on those trials in which there is no CR the UCS is omitted. That differences of procedure of this kind on half the trials should have such a large effect on conditioning perform- ance must be regarded as remarkable, and would indicate that instrumental factors can play a powerful role in eyelid conditioning.

The level of performance of the CPD group can also be compared to a group in an experiment by Gormezano \& Moore (1965). In the Gormezano study, it was arranged that the air blast would fall on the closed lid during the eyeblink response. As compared to appropriate control groups in the two experiments, the level of responding by our CPD group was very much higher. This would seem to indicate that an air puff on a naked cornea following a response has a greater effect on percentage of responding than an air puff which is always successfully avoided, in the sense that it always falls on the closed eyelid.

These results would suggest that the whole question of nonreinforcement be re-examined in aversive conditioning situations. It may be that defining nonreinforcement as the presentation of UCS following a successful or partially-successful avoidance response is more appropriate than defining it in terms of omission of the UCS which also involves changes in drive. References

Gormezano, I., \& Moore, John W. Yoked comparisons of contingent and noncontingent US presentations in human eyelid conditioning. Psychon. Sci., 1964, 1, 231-232.

Moore, John W., \& Gormezano, I. Effects of omitted versus delayed UCS on classical eyelid conditioning under partial reinforcement. J. exp. Psychol., 1963, 65, 248-257.

Spence, K. W. Learning and performance in eyelid conditioning as a function of the intensity of the UCS. J. exp. Psychol., 1953, $45,57-63$.

Spence, K. W. Behavior theory and learning. Englewood Cliffs: Prentice;Hall, 1960.

\section{Note}

1. This study was supported by a grant from the National Research Council of Canada. 